\title{
SYNTHESIS, STRUCTURAL CHARACTERIZATION AND ENZYME INHIBITION STUDIES ON 5-(2-NITROSTYRYL)-1,3,4-OXADIAZOLE-2-THIOL DERIVATIVES
}

\author{
MUHAMMAD ATHAR ABBASI*,a, ADNAN AKHTAR ${ }^{a}$, AZIZ-UR-REHMAN ${ }^{a}$, KHADIJA NAFEESA ${ }^{a}$, SABAHAT \\ ZAHRA SIDDIQUI ${ }^{a}$, KHALID MOHAMMED KHAN ${ }^{b}$, MUHAMMAD ASHRAF $^{c}$, AND SYEDA ABIDA EJAZ
}

\author{
a Department of Chemistry, Government College University, Lahore-54000, Pakistan. \\ ${ }^{b}$ HEJ Research Institute of Chemistry, International Center for Chemical and Biological Sciences, University of Karachi, Karachi-75270, Pakistan \\ ${ }^{c}$ Department of Biochemistry and Biotechnology; dDepartment of Pharmacy, The Islamia University of Bahawalpur, Bahawalpur-63100, Pakistan. \\ (Received: November 21, 2013 - Accepted: August 6, 2013)
}

\begin{abstract}
In the present work, $S$-substituted derivatives of 5-(2-nitrostyryl)-1,3,4-oxadiazole-2-thiol (4) were synthesized by successive conversions of 3-(2-nitrophenyl) acrylic acid (1) into its respective ester, hydrazide and 1,3,4-oxadiazole. Finally the target compounds were obtained by reaction of 5-(2-nitrostyryl)-1,3,4oxadiazole-2-thiol (4) with a series of various electrophiles, (5a-I), in $N, N$-dimethyl formamide (DMF) in the presence of sodium hydride (NaH). The structural characterization of these newly synthesized compounds was done by IR, ${ }^{1} \mathrm{H}-\mathrm{NMR}$, HR-MS and EI-MS spectral data. All these compounds were evaluated for their enzyme inhibitory potentials and found to exhibit broad range spectrum against acetylcholinesterase, butyrylcholinestrase and lipoxygenase enzymes.
\end{abstract}

Keywords: 3-(2-nitrophenyl)acrylic acid, 5-(2-nitrostyryl)-1,3,4-oxadiazole-2-thiol, ${ }^{1} \mathrm{H}-\mathrm{NMR}$, EI-MS, enzymatic activities.

\section{INTRODUCTION}

1,3,4-oxadiazole is a versatile group of heterocyclic compounds that have attracted attention for last two decades because of their broad range biological effectiveness. ${ }^{1}$ It is derived from furan when the replacement of two methine $(-\mathrm{CH}=)$ is done by two pyridine like nitrogen $(-\mathrm{N}=)$ at position 3 and 4. ${ }^{2}$ Aromaticity of oxadiazole ring is reduced because of this replacement due to which oxadiazole ring bears properties of conjugated diene. The electrophilic substitutions reactions in oxadiazole ring are very difficult at carbon atom due to low electron density at carbon atom. Conversely the attack of electrophiles can occur at nitrogen atom. Nucleophilic attack can occur if substitution of ring is done with electron releasing groups. Oxadiazole normally do not undergo nucleophilic attack. However halogen substituted oxadiazole undergo nucleophilic substitution reactions. Nucleophilic substitution reactions in oxadiazole are same as occurred at $s p^{2}$ carbon atom of an aliphatic compound. Extra heteroatom has inductive effect due to which oxadiazole acts as very weak base. ${ }^{3} 1,3,4$-oxadiazole can be used as a skeleton in medicinal chemistry to synthesize large number of bioactive agents. ${ }^{4} 2,5$ - disubstituted-1,3,4Oxadiazole derivatives have possessed broad range of biological activities such as antifungal, ${ }^{5}$ antimicrobial,${ }^{6,7}$ anti-inflammatory, ${ }^{2,8}$ and antiparasitic. ${ }^{9}$ HIV replication is inhibited by the use of 2,5 -disubstituted derivatives of 1,3,4-oxadiazole. ${ }^{10}$ Several 2,5-disubstituted-1,3,4-oxadiazole derivatives have powerful effect against 60 malignant tumor cell lines. Biological effects demonstrate a very significant anti-tumor activity against leukemia, breast cancer and colon. ${ }^{11,12}$ It is extensively used in the treatment of arthritis (jaundice, rheumatoid and osteoarthritis). ${ }^{13,14}$ Oxadiazole also exhibit herbicidal, ${ }^{15}$ pesticidal, analgesic ${ }^{16}$ and plant growth regulatory activities. ${ }^{17}$

Literature survey showed that slight modifications in the structure of $1,3,4$-oxadiazole can result in quantitative as well as qualitative variations in the biological activity. So in continuation of our work ${ }^{18,19}$ to search for the enzyme inhibitors bearing 1,3,4-oxadiazole nucleus, here we report a series of $S$-substituted derivatives of 5-(2-nitrostyryl)-1,3,4-oxadiazole-2-thiol (4) derived from 3-(2-nitrophenyl)acrylic acid (1) and screened results of enzyme inhibition activities for all the synthesized compounds.

\section{EXPERIMENTAL}

\subsection{Chemistry}

Griffin and George melting point apparatus was used to record the melting points of the synthesized compounds by open capillary tube and were uncorrected. Purity was checked on thin layer chromatography (TLC) on precoated silica gel G-25-UV254 plates using different percentage of ethyl acetate and $n$-hexane giving single spot. Jasco-320-A spectrophotometer was used for the IR spectra (wave number in $\mathrm{cm}^{-1}$ ). ${ }^{1} \mathrm{H}$-NMR spectra were recorded in $\mathrm{CD}_{3} \mathrm{OD}$ or $\mathrm{CDCl}_{3}$ on a Bruker spectrometers operating at 300 and $400 \mathrm{MHz}$. Chemical shifts were recorded in ppm. Mass spectra (HE-MS \& EIMS) were taken on a JMS-HX-110 spectrometer, with complete data system.
2.2. Procedure for the preparation of Ethyl-3-(2-nitrophenyl) acrylate

3-(2-nitrophenyl)acrylic acid $(1 \mathrm{~g} ;(\mathbf{1}))$ was taken into a $100 \mathrm{~mL}$ round bottom flask fitted with a reflux condenser, then absolute ethanol $(4 \mathrm{~mL})$ and conc. sulphuric acid $(1 / 2 \mathrm{~mL})$ were added into flask and the reaction mixture was refluxed for about 1 hour. The reaction was monitored by thin layer chromatography (TLC). When the reaction was completed, the reaction mixture was neutralized with concentrated solution of sodium carbonate $\left(\mathrm{Na}_{2} \mathrm{CO}_{3}\right)$. From this mixture, the desired ester was extracted with ether. This ethereal layer was evaporated to afford yellowish brown crystalline substance, ethyl-3-(2-nitrophenyl)acrylate (2).

2.3. Procedure for the preparation of 3-(2-nitrophenyl) acrylohydrazide

The methanolic solution of ethyl-3-(2-nitrophenyl)acrylate $(0.01 \mathrm{~mol}$, $2.21 \mathrm{~g}$, (2) was taken in a round bottom flask. Hydrazine hydrate $(0.03 \mathrm{~mol}$, $1.47 \mathrm{~mL}$ ) was added drop wise in this solution with stirring for $3 \mathrm{~h}$ at room temperature. Completion of reaction was checked by TLC. After completion, distilled water was added and precipitates of 3-(2-nitrophenyl)acrylohydrazide (3) formed, were filtered and re-washed with water.

2.4. Procedure for the preparation of 5-(2-nitrostyryl)-1,3,4oxadiazole-2-thiol (4)

3-(2-Nitrophenyl)acrylohydrazide. (2.07 g, 0.01mol, 3) was solubilized in absolute ethanol $(12 \mathrm{~mL})$ in $250 \mathrm{~mL}$ round bottom flask and potassium hydroxide $(1.68 \mathrm{~g}, 0.03 \mathrm{~mol})$ was added in the reaction mixture. Upon complete dissolution of potassium hydroxide, carbon disulfide $(1.81 \mathrm{~mL}, 0.03 \mathrm{~mol})$ was added to the solution. This reaction mixture was well stirred and refluxed for $6 \mathrm{~h}$ Initially the color of solution was yellow which turned to brownish yellow with the progress of reaction. Evolution of hydrogen sulfide gas occurred during this reaction. After the completion of this reaction, it was diluted with water and acidified by concentrated hydrochloric acid to $\mathrm{pH} 2-3$. The precipitates formed, were filtered and washed with water. Re-crystallization was done with ethanol to afford purified sample of 5-(2-nitrostyryl)-1,3,4-oxadiazole-2-thiol (4).

1.1.1 5-(2-nitrostyryl)-1,3,4-oxadiazole-2-thiol (4)

Yellowish brown solid; m.p. $190-192{ }^{\circ} \mathrm{C}$; yield $79 \%$; IR $\left(\mathrm{KBr}, v_{\mathrm{m}} \mathrm{cm}^{-1}\right)$ : $3200(\mathrm{~S}-\mathrm{H}), 3056(\mathrm{Ar}-\mathrm{H}), 1680(\mathrm{C}=\mathrm{N}), 1550(\mathrm{Ar} \mathrm{C}=\mathrm{C}), 1530\left(\mathrm{NO}_{2}\right), 840(\mathrm{C}-$ $\mathrm{N}) ;{ }^{1} \mathrm{H}-\mathrm{NMR}\left(300 \mathrm{MHz}, \mathrm{CD}_{3} \mathrm{OD}\right): \delta 8.06(\mathrm{dd}, J=8.1,1.2 \mathrm{~Hz}, 1 \mathrm{H}, \mathrm{H}-3$ '), 7.89 (d, $\left.J=16.2 \mathrm{~Hz}, 1 \mathrm{H}, \mathrm{H}-8^{\prime}\right), 7.76$ (dd, $\left.J=7.8,1.8 \mathrm{~Hz}, 1 \mathrm{H}, \mathrm{H}-6^{\prime}\right), 7.74$ (br t, $J$ $\left.=7.8, \mathrm{~Hz}, 1 \mathrm{H}, \mathrm{H}-4^{\prime}\right), 7.61$ (ddd, $J=8.4,8.4,1.2 \mathrm{~Hz}, 1 \mathrm{H}, \mathrm{H}-5$ '), 6.95 (d, $J=$ $16.2 \mathrm{~Hz}, 1 \mathrm{H}, \mathrm{H}-7$ '); ${ }^{13} \mathrm{C}-\mathrm{NMR}$ (75 MHz, CD $\mathrm{OD}$ ): $\delta 164.5$ (C-2), 163.7 (C-5), 149.3 (C-2'), 138.3 (C-7'), 135.5 (C-5'), 134.3 (C-1'), 132.6 (C-4'), 129.6 (C6'), 126.9 (C-3'), 110.8 (C-8'); HR-MS: [M] 249.2685 (Calcd. for $\mathrm{C}_{10} \mathrm{H}_{7} \mathrm{~N}_{3} \mathrm{O}_{3}$;

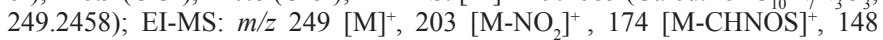
$\left[\mathrm{M}-\mathrm{C}_{2} \mathrm{HN}_{2} \mathrm{OS}\right]^{+}, 135\left[\mathrm{M}-\mathrm{C}_{3} \mathrm{H}_{2} \mathrm{~N}_{2} \mathrm{OS}\right]^{+}, 122\left[\mathrm{M}-\mathrm{C}_{4} \mathrm{H}_{3} \mathrm{~N}_{2} \mathrm{OS}\right]^{+}$.

2.5. General procedure for the preparation of S-substituted derivatives (6a-n) of 5-(2-nitrostyryl)-1,3,4-0xadiazole-2-thiol (4)

The calculated amount of 5-(2-nitrostyryl)-1,3,4-oxadiazole-2-thiol $(0.2 \mathrm{~g}$, $0.0008 \mathrm{~mol},(4)$ was taken in a $50 \mathrm{~mL}$ round bottom flask and $10 \mathrm{~mL}$ of $N, N$ dimethyl formamide (DMF) was added in order to dissolve it completely. Then 
Lithium hydride $(0.0064 \mathrm{~g}, 0.0008 \mathrm{~mol})$ was added to the mixture as base. The reaction mixture was stirred for 30 minutes at room temperature and then respective alkyl halide $(0.0008 \mathrm{~mol},(\mathbf{5 a}-\mathbf{n})$ was added to the reaction mixture and it was further stirred for $3 \mathrm{~h}$. The progress of reaction was monitored by TLC test till single spot. Then few drops of 5\% solution of sodium hydroxide were added to covert the unreacted oxadiazole-2-thiol into its salt. Finally, the addition of distilled water into this solution resulted in the formation of precipitates of respective $S$-substituted derivative (6a-n) of parent molecule. Precipitates were filtered and washed with water and dried to carry out further studies.

2.5.1. 2-(Ethylthio)-5-(2-nitrostyryl)-1,3,4-oxadiazole (6a)

Brownish yellow amorphous solid; m.p. $84-86^{\circ} \mathrm{C}$; yield $84 \%$; IR $(\mathrm{KBr}$, $\left.\mathrm{cm}^{-1}\right): 3049(\mathrm{Ar}-\mathrm{H}), 1683(\mathrm{C}=\mathrm{N}), 1555(\mathrm{Ar} \mathrm{C}=\mathrm{C}), 1527\left(\mathrm{NO}_{2}\right), 844(\mathrm{C}-\mathrm{N})$; 'H-NMR (300 MHz, CD $\left.{ }_{3} \mathrm{OD}\right): \delta 8.06(\mathrm{dd}, J=8.4,1.2 \mathrm{~Hz}, 1 \mathrm{H}, \mathrm{H}-3$ '), 7.95 (d, $J=16.5 \mathrm{~Hz}, 1 \mathrm{H}, \mathrm{H}-8^{\prime}$ ), 7.93 (br d, $J=7.5, \mathrm{~Hz}, 1 \mathrm{H}, \mathrm{H}-6^{\prime}$ ), 7.75 (br t, $J$ $\left.=7.2 \mathrm{~Hz}, 1 \mathrm{H}, \mathrm{H}-4^{\prime}\right), 7.62$ (br t $\left.J=7.5 \mathrm{~Hz}, 1 \mathrm{H}, \mathrm{H}-5^{\prime}\right), 7.14(\mathrm{~d}, J=16.2 \mathrm{~Hz}$, $\left.1 \mathrm{H}, \mathrm{H}-7^{\prime}\right), 3.33$ (q, $\left.J=7.2 \mathrm{~Hz}, 2 \mathrm{H}, \mathrm{CH}_{2}-1 "\right), 1.49$ (t, $\left.J=7.2 \mathrm{~Hz}, 3 \mathrm{H}, \mathrm{CH}_{3}-2^{\prime \prime}\right)$; ${ }^{13} \mathrm{C}-\mathrm{NMR}$ (75 MHz, CD $\mathrm{OD}$ ): $\delta 164.1$ (C-2), 163.3 (C-5), 149.2 (C-2'), 138.1 (C-7'), 135.3 (C-5'), 134.1 (C-1'), 132.2 (C-4'), 129.1 (C-6'), 126.7 (C-3'), 110.3 (C-8'), 23.4 (C-1"), 16.5 (C-2"); HR-MS: [M] 277.3067 (Calcd. for $\mathrm{C}_{12} \mathrm{H}_{11} \mathrm{~N}_{3} \mathrm{O}_{3} \mathrm{~S} ; 277.2991$ ); EI-MS: $m / z 277[\mathrm{M}]^{+}, 248\left[\mathrm{M}_{-} \mathrm{C}_{2} \mathrm{H}_{5}\right], 231\left[\mathrm{M}-\mathrm{NO}_{2}\right]^{+}$,

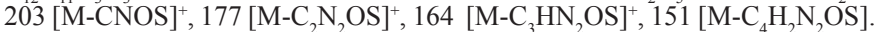

2.5.2. 2-(Isopropylthiol)-5-(2-nitrostyryl)-1,3,4-oxadiazole (6b)

Brownish yellow amorphous solid; m.p. $68-70{ }^{\circ} \mathrm{C}$; yield $80 \%$; IR $(\mathrm{KBr}$, $\left.v_{\max } \mathrm{cm}^{-1}\right): 3059(\mathrm{Ar}-\mathrm{H}), 1686(\mathrm{C}=\mathrm{N}), 1557(\mathrm{Ar} \mathrm{C}=\mathrm{C}), 1533\left(\mathrm{NO}_{2}\right), 847(\mathrm{C}-\mathrm{N})$; ' ${ }^{\max }-\mathrm{NMR}\left(300 \mathrm{MHz}, \mathrm{CH}_{3} \mathrm{OD}\right): \delta 8.06$ (dd, $J=8.1,1.2 \mathrm{~Hz}, 1 \mathrm{H}, \mathrm{H}-3$ ') 7.96 (d, $J=16.8 \mathrm{~Hz}, 1 \mathrm{H}, \mathrm{H}-8^{\prime}$ ), 7.93 (br d, $J=7.2 \mathrm{~Hz}, 1 \mathrm{H}, \mathrm{H}-6^{\prime}$ '), 7.76 (br t, $J=7.2$ $\left.\mathrm{Hz}, 1 \mathrm{H}, \mathrm{H}-4^{\prime}\right), 7.62$ (ddd, $J=8.4,8.1,0.9 \mathrm{~Hz}, 1 \mathrm{H}, \mathrm{H}-5$ '), 7.14 (d, $J=16.2 \mathrm{~Hz}$, $1 \mathrm{H}, \mathrm{H}-7^{\prime}$ ), 3.94 (septet, $J=6.9 \mathrm{~Hz}, 1 \mathrm{H}, \mathrm{H}-1$ "), 1.51 (d, $J=6.6 \mathrm{~Hz}, 6 \mathrm{H}, \mathrm{CH}_{3}-2$ ", $\mathrm{CH}_{3}-3$ "); ${ }^{13} \mathrm{C}-\mathrm{NMR}$ (75 MHz, CD OD): $\delta 164.3$ (C-2), 163.5 (C-5), 148.9 (C2'), 138.3 (C-7'), 135.6 (C-5'), 133.7 (C-1'), 132.5 (C-4'), 129.5 (C-6'), 126.3 (C-3'), 109.8 (C-8'), 37.2 (C-1"), 23.9 (C-2" \& C-3"); HR-MS: M] 291.3367 (Calcd. for $\mathrm{C}_{13} \mathrm{H}_{13} \mathrm{~N}_{3} \mathrm{O}_{3} \mathrm{~S} ; 291.3256$ ); EI-MS: $\mathrm{m} / z 291[\mathrm{M}]^{+}, 245\left[\mathrm{M}-\mathrm{NO}_{2}\right]^{+}$, $248\left[\mathrm{M}-\mathrm{C}_{3} \mathrm{H}_{7}\right]^{+}, 217[\mathrm{M}-\mathrm{CNOS}]^{+}, 191\left[\mathrm{M}-\mathrm{C}_{2} \mathrm{~N}_{2} \mathrm{OS}\right]^{+}, 178\left[\mathrm{M}-\mathrm{C}_{3} \mathrm{HN}_{2} \mathrm{OS}\right]^{+}, 165$ $\left[\mathrm{M}-\mathrm{C}_{4} \mathrm{H}_{2} \mathrm{~N}_{2} \mathrm{OS}\right]$

2.5.3. 5-(2-Nitrostyryl)-2-(vinylthio)-1,3,4-oxadiazole (6c)

Off-white amorphous solid; m.p. $92-94{ }^{\circ} \mathrm{C}$; yield $78 \%$; IR $\left(\mathrm{KBr}, v_{\mathrm{moc}} \mathrm{cm}^{-1}\right)$ : $3056(\mathrm{Ar}-\mathrm{H}), 1684(\mathrm{C}=\mathrm{N}), 1553(\mathrm{Ar} \mathrm{C}=\mathrm{C}), 1526\left(\mathrm{NO}_{2}\right), 848(\mathrm{C}-\mathrm{N}) ;{ }^{\max } \mathrm{H}-\mathrm{NMR}$ $\left(400 \mathrm{MHz}, \mathrm{CDCl}_{3}\right): \delta 8.05\left(\mathrm{~d}, J=8.0 \mathrm{~Hz}, 1 \mathrm{H}, \mathrm{H}-3^{\prime}\right), 7.94(\mathrm{~d}, J=16.4 \mathrm{~Hz}, 1 \mathrm{H}$, H-8'), 7.68 (m, 2H, H-4', H-6'), 7.54 (br t, $J=7.4 \mathrm{~Hz}, 1 \mathrm{H}, \mathrm{H}-5^{\prime}$ ), 6.98 (d, $J$ $\left.=16.4 \mathrm{~Hz}, 1 \mathrm{H}, \mathrm{H}-7^{\prime}\right), 6.88$ (dd, $\left.J=16.8,9.6 \mathrm{~Hz}, 1 \mathrm{H}, \mathrm{H}-1^{\prime \prime}\right), 5.76$ (br d, $J=$ $17.2 \mathrm{~Hz}, 1 \mathrm{H}, \mathrm{H}_{\mathrm{b}}-2$ "), 5.72 (br d, $\left.J=9.6 \mathrm{~Hz}, 1 \mathrm{H}, \mathrm{H}-2 "\right) ;{ }^{13} \mathrm{C}-\mathrm{NMR}(75 \mathrm{MHz}$, CD $\mathrm{OD}$ ): $\delta 164.2$ (C-2), 163.7 (C-5), 148.6 (C-2'), 138.8 (C-7'), 135.2 (C-5'), 133.5 (C-1'), 132.9 (C-4'), 131.5 (C-1'), 129.6 (C-6'), 126.6 (C-3'), 116.9 (C2"), 109.6 (C-8'); HR-MS: [M] 275.2997 (Calcd. for $\mathrm{C}_{12} \mathrm{H}_{9} \mathrm{~N}_{3} \mathrm{O}_{3} \mathrm{~S}$; 275.2831 );

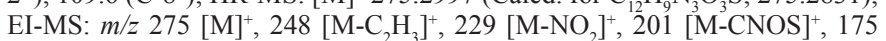
$\left[\mathrm{M}-\mathrm{C}_{2} \mathrm{~N}_{2} \mathrm{OS}\right]^{+}, 162\left[\mathrm{M}-\mathrm{C}_{3} \mathrm{HN}_{2} \mathrm{OS}\right]^{+}, 149\left[\mathrm{M}-\mathrm{C}_{4} \mathrm{H}_{2} \mathrm{~N}_{2} \mathrm{OS}\right]$.

\subsubsection{2-(Allylthio)-5-(2-Nitrostyryl)-1,3,4-oxadiazole (6d)}

Yellow amorphous solid; m.p. $75-77^{\circ} \mathrm{C}$; yield $81 \%$; IR $\left(\mathrm{KBr}, v \mathrm{~cm}^{-1}\right)$ : $3056(\mathrm{Ar}-\mathrm{H}), 1688(\mathrm{C}=\mathrm{N}), 1554(\mathrm{Ar} \mathrm{C}=\mathrm{C}), 1539\left(\mathrm{NO}_{2}\right), 846(\mathrm{C}-\mathrm{N}) ;{ }^{\max } \mathrm{H}-\mathrm{NMR}$ (300 MHz, CD OD): $\delta 8.06$ (dd, $J=8.1,1.2 \mathrm{~Hz}, 1 \mathrm{H}, \mathrm{H}-3$ ') 7.96 (d, $J=16.2$ $\mathrm{Hz}, 1 \mathrm{H}, \mathrm{H}-8^{\prime}$ ), 7.92 (br d, $\left.J=7.5 \mathrm{~Hz}, 1 \mathrm{H}, \mathrm{H}-6^{\prime}\right), 7.75$ (br t, $J=7.8 \mathrm{~Hz}, 1 \mathrm{H}$, H-4') 7.62 (ddd, $\left.J=8.7,8.1,1.5 \mathrm{~Hz}, 1 \mathrm{H}, \mathrm{H}-5^{\prime}\right), 7.14(\mathrm{~d}, J=16.2 \mathrm{~Hz}, 1 \mathrm{H}$, H-7'), 6.04 (m, 1H, H-2"), 5.39 (dd, $J=17.1,1.2 \mathrm{~Hz}, 1 \mathrm{H}, \mathrm{H}_{\mathrm{b}}-3$ "), 5.20 (dd, $J=9.9,0.6 \mathrm{~Hz}, 1 \mathrm{H}, \mathrm{H}-3$ "), $3.93\left(\mathrm{~d}, J=7.2 \mathrm{~Hz}, 2 \mathrm{H}, \mathrm{CH}_{2}-1\right.$ "); ${ }^{13} \mathrm{C}-\mathrm{NMR}(75$ MHz, CD $\mathrm{OD}$ ): $\delta 164.6$ (C-2), 163.9 (C-5), 148.4 (C-2'), 138.7 (C-7'), 135.2 (C-5'), 133.4 (C-1'), 132.1 (C-4'), 129.8 (C-6'), 127.2 (C-2'), 126.7 (C-3'), 119.8 (C-3"), 110.8 (C-8'), 36.9 (C-1"); HR-MS: [M] 289.3286 (Calcd. for

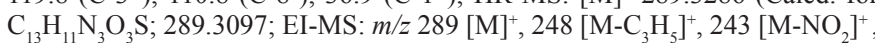

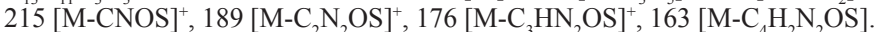

2.5.5. 5-(2-Nitrostyryl)-2-(phenylethylthio)-1,3,4-0xadiazole (6e)

Off-white amorphous powder; m.p. $85-87{ }^{\circ} \mathrm{C}$; yield $70 \%$; IR (KBr, $v_{\text {max }}$ $\left.\mathrm{cm}^{-1}\right): 3056(\mathrm{Ar}-\mathrm{H}), 1680(\mathrm{C}=\mathrm{N}), 1550(\mathrm{Ar} \mathrm{C}=\mathrm{C}), 1532\left(\mathrm{NO}_{2}\right), 844(\mathrm{C}-\mathrm{N})$; ${ }^{1} \mathrm{H}-\mathrm{NMR}\left(400 \mathrm{MHz}, \mathrm{CDCl}_{3}\right): \delta 8.05$ (d, $J=8.0 \mathrm{~Hz}, 1 \mathrm{H}, \mathrm{H}-3$ ') 7.91 (d, $J=16.0$ Hz, 1H, H-8'), 7.69 (m, 2H, H-4', H-6'), 7.54 (br t, $J=8.4$ Hz, 1H, H-5'), 7.30 (br d, $J=7.2 \mathrm{~Hz}, 2 \mathrm{H}, \mathrm{H}-2$ ", H-6"), 7.24 (m, 3H, H-3" to H-5"), 6.97 (d, $J=$ $\left.16.4 \mathrm{~Hz}, 1 \mathrm{H}, \mathrm{H}-7^{\prime}\right), 3.52$ (t, $\left.J=7.2 \mathrm{~Hz}, 2 \mathrm{H}, \mathrm{CH}_{2}-8^{\prime \prime}\right), 3.14$ (t, $J=7.12 \mathrm{~Hz}, 2 \mathrm{H}$, $\mathrm{CH}_{2}-7$ '); ${ }^{13} \mathrm{C}-\mathrm{NMR}\left(75 \mathrm{MHz}, \mathrm{CD}_{3} \mathrm{OD}\right): \delta 165.6(\mathrm{C}-2), 163.5(\mathrm{C}-5), 148.9$ (C2'), 140.5 (C-1'), 138.5 (C-7'), 135.6 (C-5'), 133.7 (C-1'), 132.6 (C-4'), 131.7 (C-3" \& C-5"), 129.9 (C-6'), 129.5 (C-2" \& C-6"), 127.4 (C-4"), 126.5 (C-3'), 110.8 (C-8'), 35.3 (C-7"), 28.5 (C-8"); HR-MS: [M] 353.4072 (Calcd. for $\left.\mathrm{C}_{18} \mathrm{H}_{15} \mathrm{~N}_{3} \mathrm{O}_{3} \mathrm{~S} ; 353.3951\right)$; EI-MS: $m / z 353[\mathrm{M}]^{+}, 307\left[\mathrm{M}-\mathrm{NO}_{2}\right]^{+}, 262\left[\mathrm{M}-\mathrm{C}_{7} \mathrm{H}_{7}\right]^{+}$,

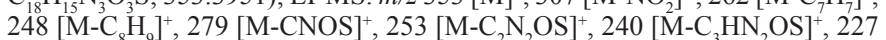

\section{$\left[\mathrm{M}-\mathrm{C}_{4} \mathrm{H}_{2} \mathrm{~N}_{2} \mathrm{OS}\right]$.}

2.5.6. 5-(2-Nitrostyryl)-2-(3-phenylpropylthio)-1,3,4-oxadiazole (6f)

Yellow amorphous solid; m.p. $78-80{ }^{\circ} \mathrm{C}$; yield $80 \%$; IR $\left(\mathrm{KBr}, v_{\max } \mathrm{cm}^{-1}\right)$ : $3051(\mathrm{Ar}-\mathrm{H}), 1684(\mathrm{C}=\mathrm{N}), 1558(\mathrm{Ar} \mathrm{C}=\mathrm{C}), 1531\left(\mathrm{NO}_{2}\right), 843(\mathrm{C}-\mathrm{N}) ;{ }^{\max } \mathrm{H}-\mathrm{NMR}$ (400 MHz, $\mathrm{CDCl}_{3}$ ): $\delta 8.05$ (d, $\left.J=8.0 \mathrm{~Hz}, 1 \mathrm{H}, \mathrm{H}-3^{\prime}\right), 7.90(\mathrm{~d}, J=16.0 \mathrm{~Hz}, 1 \mathrm{H}$, H-8'), 7.67 (m, 2H, H-4', H-6'), 7.55 (br t, $J=8.0 \mathrm{~Hz}, 1 \mathrm{H}, \mathrm{H}-5$ '), 7.26 (t, $J=$ $6.8 \mathrm{~Hz}, 3 \mathrm{H}, \mathrm{H}-3$ ", H-4", H-5"), 7.19 (br d, $J=6.8 \mathrm{~Hz}, 2 \mathrm{H}, \mathrm{H}-2$ ", H-6"), 6.97 (d, $\left.J=16.0 \mathrm{~Hz}, 1 \mathrm{H}, \mathrm{H}-7^{\prime}\right), 3.28$ (t, $\left.J=7.2 \mathrm{~Hz}, 2 \mathrm{H}, \mathrm{CH}_{2}-9^{\prime \prime}\right), 2.79$ (t, $J=7.2,2 \mathrm{H}$, $\mathrm{CH}_{2}-7$ "), 2.17 (quint., $J=7.6 \mathrm{~Hz}, 2 \mathrm{H}, \mathrm{CH}_{2}-8$ "); ${ }^{13} \mathrm{C}-\mathrm{NMR}\left(75 \mathrm{MHz}, \mathrm{CD}_{3} \mathrm{OD}\right)$ :

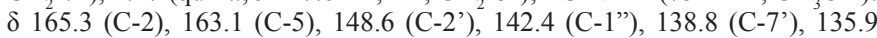
(C-5'), 133.7 (C-1'), 132.7 (C-4'), 131.5 (C-2"' \& C-6”), 129.9 (C-6'), 129.5 (C-3" \& C-5"), 126.7 (C-4”), 126.3 (C-3'), 110.8 (C-8'), 33.9 (C-7”), 30.4 (C8”), 27.8 (C-9"); HR-MS: [M] 367.4401 (Calcd. for $\mathrm{C}_{19} \mathrm{H}_{17} \mathrm{~N}_{3} \mathrm{O}_{3} \mathrm{~S}$; 367.4216); EI-MS: $m / z 367[\mathrm{M}]^{+} 321\left[\mathrm{M}-\mathrm{NO}_{2}\right]^{+}, 276\left[\mathrm{M}-\mathrm{C}_{7} \mathrm{H}_{7}\right]^{+}, 248\left[{ }^{3} \mathrm{M}^{3} \mathrm{C}_{9} \mathrm{H}_{11}\right]^{+}, 293$ $[\mathrm{M}-\mathrm{CNOS}]^{+}, 267\left[\mathrm{M}-\mathrm{C}_{2} \mathrm{~N}_{2} \mathrm{OS}\right]^{+}, 254\left[\mathrm{M}-\mathrm{C}_{3} \mathrm{HN}_{2} \mathrm{OS}\right]^{+}, 241\left[\mathrm{M}-\mathrm{C}_{4} \mathrm{H}_{2} \mathrm{~N}_{2} \mathrm{OS}\right]$.

2.5.7. 2-(Benzylthio)-5-(2-nitrostyryl)-1,3,4-oxadiazole (6g)

Brownish yellow amorphous solid; m.p. $128-130{ }^{\circ} \mathrm{C}$; yield $73 \%$; IR $(\mathrm{KBr}$, $\left.v_{\max } \mathrm{cm}^{-1}\right): 3051(\mathrm{Ar}-\mathrm{H}), 1685(\mathrm{C}=\mathrm{N}), 1559(\mathrm{Ar} \mathrm{C}=\mathrm{C}), 1532\left(\mathrm{NO}_{2}\right), 847(\mathrm{C}-\mathrm{N})$; ${ }^{1} \mathrm{H}-\mathrm{NMR}\left(400 \mathrm{MHz}, \mathrm{CDCl}_{3}\right): \delta 8.04(\mathrm{~d}, J=8.0 \mathrm{~Hz}, 1 \mathrm{H}, \mathrm{H}-3$ '), 7.89 (d, $J=16.0$ $\mathrm{Hz}, 1 \mathrm{H}, \mathrm{H}-8^{\prime}$ ), 7.67 (br d, $J=7.6 \mathrm{~Hz}, 2 \mathrm{H}, \mathrm{H}-4^{\prime}, \mathrm{H}^{\prime} 6^{\prime}$ ), 7.53 (ddd, $J=8.4,7.8$, $1.6 \mathrm{~Hz}, 1 \mathrm{H}, \mathrm{H}-3$ ') 7.44 (br d, $J=7.2 \mathrm{~Hz}, 2 \mathrm{H}, \mathrm{H}-2$ ”, H-6"), 7.28-7.34 (m, 3H, H-3" to H-5"), 6.96 (d, $J=16.0 \mathrm{~Hz}, 1 \mathrm{H}, \mathrm{H}-7$ '), 4.50 (s, 2H, CH -7"); ${ }^{13} \mathrm{C}-\mathrm{NMR}$ (75 MHz, CD $\mathrm{OD}$ ): $\delta 165.7$ (C-2), 163.5 (C-5), 148.2 (C-2'), 138.4 (C-7'), 137.5 (C-1”), 135.6 (C-5'), 133.5 (C-1'), 132.4 (C-4'), 129.7 (C-6'), 129.4 (C-3" \& C-5”), 128.5 (C-2" \& C-6”), 128.1 (C-4"), 126.5 (C-3'), 110.5 (C8'), 32.5 (C-7"); HR-MS [M] 339.3827 (Calcd. for $\mathrm{C}_{17} \mathrm{H}_{13} \mathrm{~N}_{3} \mathrm{O}$ S; 339.3684 );

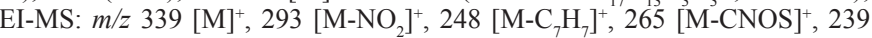
$\left[\mathrm{M}-\mathrm{C}_{2} \mathrm{~N}_{2} \mathrm{OS}\right]^{+}, 226\left[\mathrm{M}-\mathrm{C}_{3} \mathrm{HN}_{2} \mathrm{OS}\right]^{+}, 213\left[\mathrm{M}-\mathrm{C}_{4} \mathrm{H}_{2} \mathrm{~N}_{2} \mathrm{OS}\right]$.

2-(2-Methylbenzylthio)-5-(2-nitrostyryl)-1,3,4-oxadiazole (6h)

Off-white amorphous solid; m.p. $148-150{ }^{\circ} \mathrm{C}$; yield $78 \%$; IR $\left(\mathrm{KBr}, v_{\max }\right.$ $\left.\mathrm{cm}^{-1}\right)$ : $3050(\mathrm{Ar}-\mathrm{H}), 1686(\mathrm{C}=\mathrm{N}), 1552(\mathrm{Ar} \mathrm{C}=\mathrm{C}), 1534\left(\mathrm{NO}_{2}\right), 846(\mathrm{C}-\mathrm{N})$; ${ }^{1} \mathrm{H}-\mathrm{NMR}\left(400 \mathrm{MHz}, \mathrm{CDCl}_{3}\right): \delta 8.04\left(\mathrm{~d}, J=8.0 \mathrm{~Hz}, 1 \mathrm{H}, \mathrm{H}-3^{\prime}\right), 7.91(\mathrm{~d}, J=$ $\left.16.4 \mathrm{~Hz}, 1 \mathrm{H}, \mathrm{H}-8^{\prime}\right), 7.69$ (m, 2H, H-4', H-6'), 7.53 (br t, $J=8.4 \mathrm{~Hz}, 1 \mathrm{H}$, H-5'), 7.40 (br d, $J=7.2 \mathrm{~Hz}, 1 \mathrm{H}, \mathrm{H}-4$ "), 7.20 (m, 3H, H-3" to H-6"), 6.97 (d, $\left.J=16.4 \mathrm{~Hz}, 1 \mathrm{H}, \mathrm{H}-7^{\prime}\right), 4.45$ (s, 2H, $\left.\mathrm{CH}_{2}-7^{\prime \prime}\right), 2.44$ (s, 3H, CH -8 "); ${ }^{13} \mathrm{C}-\mathrm{NMR}$ (75 MHz, CD $\mathrm{OD}$ ): $\delta 165.1$ (C-2), 163.5 (C-5), 148.9 (C-2'), 141.4 (C-1"), 138.6 (C-7'), 136.3 (C-2”), 135.6 (C-5'), 134.2 (C-3”), 133.6 (C-1'), 132.5 (C-4'), 129.9 (C-4"), 129.7 (C-6"), 129.6 (C-6'), 127.5 (C-5"), 126.5 (C-3'), 110.5 (C-8'), 28.5 (C-7”), 19.5 (C-8”); HR-MS: [M] 353.4121 (Calcd. for $\mathrm{C}_{18} \mathrm{H}_{15} \mathrm{~N}_{3} \mathrm{O}_{3} \mathrm{~S} ; 353.3951$ ); EI-MS: $m / z 353[\mathrm{M}]^{+}, 338\left[\mathrm{M}-\mathrm{CH}_{3}\right]^{+}, 307\left[\mathrm{M}-\mathrm{NO}_{2}\right]^{+}$, $248\left[\mathrm{M}-\mathrm{C}_{8} \mathrm{H}_{9}\right]^{+}, 279[\mathrm{M}-\mathrm{CNOS}]^{+}, 253\left[\mathrm{M}-\mathrm{C}_{2} \mathrm{~N}_{2} \mathrm{OS}\right]^{+}, 240\left[\mathrm{M}-\mathrm{C}_{3} \mathrm{HN}_{2} \mathrm{OS}\right]^{+}, 227$ $\left[\mathrm{M}-\mathrm{C}_{4} \mathrm{H}_{2} \mathrm{~N}_{2} \mathrm{OS}\right]$.

2.5.8. 2-(4-Fluorobenzylthio)-5-(2-nitrostyryl)-1,3,4-oxadiazole (6i)

Off-white amorphous solid; m.p. $141-143{ }^{\circ} \mathrm{C}$; yield $79 \%$; IR (KBr, $v$ $\left.\mathrm{cm}^{-1}\right)$ : $3059(\mathrm{Ar}-\mathrm{H}), 1686(\mathrm{C}=\mathrm{N}), 1553(\mathrm{Ar} \mathrm{C}=\mathrm{C}), 1536\left(\mathrm{NO}_{2}\right), 842(\mathrm{C}-\mathrm{N})$; ${ }^{1} \mathrm{H}-\mathrm{NMR}\left(400 \mathrm{MHz}, \mathrm{CDCl}_{3}\right)$ : $\delta 8.05$ (d, $J=8.0 \mathrm{~Hz}, 1 \mathrm{H}, \mathrm{H}-3$ '), 7.90 (d, $J=16.0$ Hz, 1H, H-8'), 7.67 (m, 2H, H-4', H-6'), 7.55 (br t, $J=8.0$ Hz, 1H, H-5'), 7.42 (d, $J=8.4 \mathrm{~Hz}, 2 \mathrm{H}, \mathrm{H}-2$ ", H-6"), 7.02 (d, $J=8.4 \mathrm{~Hz}, 2 \mathrm{H}, \mathrm{H}-3$ ", H-5"), 6.96 (d, $\left.J=16.0 \mathrm{~Hz}, 1 \mathrm{H}, \mathrm{H}-7^{\prime}\right), 4.45$ (s, $\left.2 \mathrm{H}, \mathrm{CH}_{-}-7^{\prime \prime}\right) ;{ }^{13} \mathrm{C}-\mathrm{NMR}\left(75 \mathrm{MHz}, \mathrm{CD}_{3} \mathrm{OD}\right):$ $\delta 165.1$ (C-2), 163.3 (C-5), 162.5 (C-4'), 148.8 (C-2'), 138.5 (C-7'), 135.7 (C-5'), 133.5 (C-1'), 132.4 (C-4'), 132.6 (C-2" \& C-6"), 131.7 (C-1"), 129.7 (C-6'), 126.7 (C-3'), 115.6 (C-3"' \& C-5”), 110.5 (C-8'), 32.5 (C-7'); HR-MS: $[\mathrm{M}]^{+} 357.3692$ (Calcd. for $\mathrm{C}_{17} \mathrm{H}_{12} \mathrm{FN}_{3} \mathrm{O}_{3} \mathrm{~S}$; 357.3588); EI-MS: $m / z 357[\mathrm{M}]^{+}$,

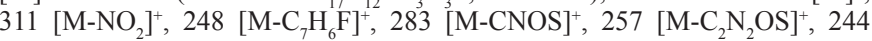
$\left[\mathrm{M}-\mathrm{C}_{3} \mathrm{HN}_{2} \mathrm{OS}\right]^{+}, 231\left[\mathrm{M}-\mathrm{C}_{4} \mathrm{H}_{2} \mathrm{~N}_{2} \mathrm{OS}\right]$.

2.5.9. 2-(2-Chlorobenzylthio)-5-(2-nitrostyryl)-1,3,4-oxadiazole (6j)

Off-white amorphous solid; m.p. $144-146{ }^{\circ} \mathrm{C}$; yield $72 \%$; IR (KBr, $v$ $\left.\mathrm{cm}^{-1}\right)$ : $3051(\mathrm{Ar}-\mathrm{H}), 1683(\mathrm{C}=\mathrm{N}), 1556(\mathrm{Ar} \mathrm{C}=\mathrm{C}), 1530\left(\mathrm{NO}_{2}\right), 848(\mathrm{C}-\mathrm{N}), 560$ (C-Cl); ${ }^{1} \mathrm{H}-\mathrm{NMR}\left(400 \mathrm{MHz}, \mathrm{CDCl}_{3}\right): \delta 8.04$ (d, $J=8.4 \mathrm{~Hz}, 1 \mathrm{H}, \mathrm{H}-3$ '), 7.90 (d, $\left.J=16.0 \mathrm{~Hz}, 1 \mathrm{H}, \mathrm{H}-8^{\prime}\right), 7.67$ (m, 2H, H-4', H-6'), 7.59 (dd, $J=8.8,2.4$, Hz, 1H, H-3"), 7.52 (ddd, $J=8.4,8.4,2.0 \mathrm{~Hz}, 1 \mathrm{H}, \mathrm{H}-5$ '), 7.40 (dd, $J=9.2$, $2.4 \mathrm{~Hz}, 1 \mathrm{H}, \mathrm{H}-6$ "), 7.24 (m, 2H, H-4", H-5"), 6.95 (d, $J=16.0 \mathrm{~Hz}, 1 \mathrm{H}, \mathrm{H}-7$ '), 4.61 (s, 2H, $\mathrm{CH}_{2}-7$ "); ${ }^{13} \mathrm{C}-\mathrm{NMR}\left(75 \mathrm{MHz}, \mathrm{CD}_{3} \mathrm{OD}\right): \delta 165.3$ (C-2), 163.4 (C5), 148.7 (C-2'), 138.3 (C-7'), 135.9 (C-5'), 135.8 (C-1'), 133.9 (C-1'), 132.4 (C-4'), 130.8 (C-5"), 130.6 (C-3"), 129.3 (C-6'), 128.9 (C-4"), 128.3 (C-6"), 127.4 (C-2”), 126.7 (C-3'), 110.7 (C-8'), 31.4 (C-7”); HR-MS: [M] 373.8314 (Calcd. for $\mathrm{C}_{17} \mathrm{H}_{12} \mathrm{ClN}_{3} \mathrm{O}_{3} \mathrm{~S} ; 373.8134$ ); EI-MS: $\mathrm{m} / z 374[\mathrm{M}]^{+}, 328\left[\mathrm{M}-\mathrm{NO}_{2}\right]^{+}$, $249\left[\mathrm{M}-\mathrm{C}_{7} \mathrm{H}_{6} \mathrm{Cl}\right]^{+}, 299[\mathrm{M}-\mathrm{CNOS}]^{+}, 273\left[\mathrm{M}^{-} \mathrm{C}_{2} \mathrm{~N}_{2} \mathrm{OS}\right]^{+}, 260\left[\mathrm{M}-\mathrm{C}_{3} \mathrm{HN}_{2} \mathrm{OS}\right]^{+}$, $247\left[\mathrm{M}-\mathrm{C}_{4} \mathrm{H}_{2} \mathrm{~N}_{2} \mathrm{OS}\right]$

2.5.10. 2-(3-Chlorobenzylthio)-5-(2-nitrostyryl)-1,3,4-oxadiazole (6k)

Light brownish yellow solid; m.p. $120-122{ }^{\circ} \mathrm{C}$; yield $75 \%$; IR (KBr, $v$ $\left.\mathrm{cm}^{-1}\right)$ : $3056(\mathrm{Ar}-\mathrm{H}), 1687(\mathrm{C}=\mathrm{N}), 1552(\mathrm{Ar} \mathrm{C}=\mathrm{C}), 1539\left(\mathrm{NO}_{2}\right), 845(\mathrm{C}-\mathrm{N}), 563$ 
(C-Cl); ${ }^{1} \mathrm{H}-\mathrm{NMR}\left(400 \mathrm{MHz}, \mathrm{CDCl}_{3}\right): \delta 8.05(\mathrm{~d}, J=8.0 \mathrm{~Hz}, 1 \mathrm{H}, \mathrm{H}-3$ ') $7.90(\mathrm{~d}, J$ $\left.=16.0 \mathrm{~Hz}, 1 \mathrm{H}, \mathrm{H}-8^{\prime}\right), 7.67$ (m, 2H, H-4', H-6'), 7.54 (ddd, $J=8.4,7.4,1.6 \mathrm{~Hz}$, 1H, H-5'), 7.44 (br s, 1H, H-2"), 7.34 (m, 1H,H-4"), 7.27 (m, 2H, H-5", H-6") $6.95\left(\mathrm{~d}, J=16.0 \mathrm{~Hz}, 1 \mathrm{H}, \mathrm{H}-7\right.$ ') 4.56 (s, $\left.2 \mathrm{H}, \mathrm{CH}_{-}-7^{\prime \prime}\right) ;{ }^{13} \mathrm{C}-\mathrm{NMR}(75 \mathrm{MHz}$, $\left.\mathrm{CD}_{3} \mathrm{OD}\right): \delta 165.5$ (C-2), 163.6 (C-5), 148.6 (C-2'), 139.6 (C-1"), 138.5 (C-7'), 136.4 (C-3"), 135.6 (C-5'), 133.6 (C-1'), 132.2 (C-4'), 130.8 (C-4"), 130.3 (C-5”), 129.5 (C-6'), 128.4 (C-2”), 126.5 (C-3'), 124.5 (C-6”), 110.3 (C-8'), 33.5 (C-7"); HR-MS: [M] 373.8314 (Calcd. for $\mathrm{C}_{11} \mathrm{H}_{12} \mathrm{ClN}_{3} \mathrm{O}_{3} \mathrm{~S}$; 373.8134);

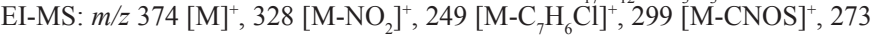
$\left[\mathrm{M}-\mathrm{C}_{2} \mathrm{~N}_{2} \mathrm{OS}\right]^{+}, 260\left[\mathrm{M}-\mathrm{C}_{3} \mathrm{HN}_{2} \mathrm{OS}\right]^{+}, 247\left[\mathrm{M}-\mathrm{C}_{4} \mathrm{H}_{2} \mathrm{~N}_{2} \mathrm{OS}\right]$.

2.5.11. 2-(4-Chlorobenzylthio)-5-(2-nitrostyryl)-1,3,4-oxadiazole (6I)

Cream yellow solid; m.p. $128-130{ }^{\circ} \mathrm{C}$; yield $76 \%$; IR $\left(\mathrm{KBr}, v_{\max } \mathrm{cm}^{-1}\right): 3053$ $(\mathrm{Ar}-\mathrm{H}), 1681(\mathrm{C}=\mathrm{N}), 1558(\mathrm{Ar} \mathrm{C}=\mathrm{C}), 1534\left(\mathrm{NO}_{2}\right), 847(\mathrm{C}-\mathrm{N}), 566(\mathrm{C}-\mathrm{Cl})$; ${ }^{1} \mathrm{H}-\mathrm{NMR}\left(\left(400 \mathrm{MHz}, \mathrm{CDCl}_{3}\right): \delta 8.05(\mathrm{~d}, J=8.0 \mathrm{~Hz}, 1 \mathrm{H}, \mathrm{H}-3\right.$ '), $7.90(\mathrm{~d}, J$ $\left.=16.4 \mathrm{~Hz}, 1 \mathrm{H}, \mathrm{H}-8^{\prime}\right), 7.68$ (m, 2H, H-4', H-6') 7.54 (ddd, $J=8.4,7.4,1.6$ Hz, 1H, H-3"), 7.39 (d, $J=8.0 \mathrm{~Hz}, 2 \mathrm{H}, \mathrm{H}-2$ ", H-6"), 7.30 (d, $J=8.4 \mathrm{~Hz}, 2 \mathrm{H}$, H-3", H-5”), 6.95 (d, $\left.J=16.0 \mathrm{~Hz}, 1 \mathrm{H}, \mathrm{H}-7^{\prime}\right), 4.45$ (s, 2H, CH $\left.-7 "\right) ;{ }^{13} \mathrm{C}-\mathrm{NMR}$ (75 MHz, CD $\mathrm{OD}$ ): $\delta 165.4$ (C-2), 163.7 (C-5), 148.6 (C-2'), 138.3 (C-7'), 136.1 (C-4”), 135.6 (C-5'), 135.2 (C-1"), 133.7 (C-1'), 132.5 (C-4'), 131.3 (C-3" \& C-5"), 129.6 (C-6'), 126.9 (C-2" \& C-6”), 126.4 (C-3'), 110.8 (C-8'), 32.7 (C-7”); HR-MS: [M] 373.8314 (Calcd. for $\mathrm{C}_{17} \mathrm{H}_{12} \mathrm{ClN}_{3} \mathrm{O}_{3} \mathrm{~S}$; 373.8134 );

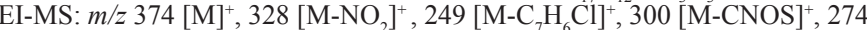
$\left[\mathrm{M}-\mathrm{C}_{2} \mathrm{~N}_{2} \mathrm{OS}\right]^{+}, 261\left[\mathrm{M}-\mathrm{C}_{3} \mathrm{HN}_{2} \mathrm{OS}\right]^{+}, 248\left[\mathrm{M}-\mathrm{C}_{4} \mathrm{H}_{2} \mathrm{~N}_{2} \mathrm{OS}\right]$.

2.5.12. 2-(4-Bromobenzylthio)-5-(2-nitrostyryl)-1,3,4-oxadiazole $(6 \mathrm{~m})$

Pale yellow amorphous solid; m.p. $110-112{ }^{\circ} \mathrm{C}$; yield $78 \%$; IR (KBr, $v_{\max }$ $\left.\mathrm{cm}^{-1}\right)$ : $3058(\mathrm{Ar}-\mathrm{H}), 1688(\mathrm{C}=\mathrm{N}), 1553(\mathrm{Ar} \mathrm{C}=\mathrm{C}), 1537\left(\mathrm{NO}_{2}\right), 844(\mathrm{C}-\mathrm{N}), 510$ (C-Br); ${ }^{1} \mathrm{H}-\mathrm{NMR}\left(400 \mathrm{MHz}, \mathrm{CDCl}_{3}\right): \delta 8.05$ (d, $J=8.0 \mathrm{~Hz}, 1 \mathrm{H}, \mathrm{H}-3$ '), 7.90 (d, $\left.J=16.0 \mathrm{~Hz}, 1 \mathrm{H}, \mathrm{H}-8^{\prime}\right), 7.68\left(\mathrm{~m}, 1 \mathrm{H}, \mathrm{H}-6^{\prime}, \mathrm{H}-4^{\prime}\right), 7.54$ (br t, $J=8.4 \mathrm{~Hz}$, $1 \mathrm{H}, \mathrm{H}-5$ '), 7.45 (d, $J=8.4 \mathrm{~Hz}, 2 \mathrm{H}, \mathrm{H}-2 ", \mathrm{H}-6 "), 7.33$ (d, $J=8.0 \mathrm{~Hz}, 2 \mathrm{H}$, H-3", H-5"), 6.95 (d, $\left.J=16.4 \mathrm{~Hz}, 1 \mathrm{H}, \mathrm{H}-7^{\prime}\right), 4.44$ (s, $\left.2 \mathrm{H}, \mathrm{CH}_{2}-7^{\prime \prime}\right) ;{ }^{13} \mathrm{C}-\mathrm{NMR}$ (75 MHz, CD $\mathrm{OD}$ ): $\delta 165.2$ (C-2), 163.4 (C-5), 148.1 (C-2'), 138.7 (C-7'), 136.2 (C-1”), 135.4 (C-5'), 133.8 (C-1'), 133.4 (C-3” \& C-5”), 132.9 (C-4'), 131.4 (C-2" \& C-6”), 129.1 (C-6'), 126.7 (C-3'), 124.2 (C-4”), 110.2 (C-8'), 32.4 (C-7"); HR-MS: [M] 418.2823 (Calcd. for $\mathrm{C}_{17} \mathrm{H}_{12} \mathrm{BrN}_{3} \mathrm{O}_{3} \mathrm{~S}$; 418.2644); EI-MS: $m / z 418\left[\mathrm{M}^{+}, 372\left[\mathrm{M}-\mathrm{NO}_{2}\right]^{+}, 248\left[\mathrm{M}-\mathrm{C}_{7} \mathrm{H}_{6} \mathrm{Br}\right]^{+}, 344[\mathrm{M}-\mathrm{CNOS}]^{+}, 318\right.$ $\left[\mathrm{M}-\mathrm{C}_{2} \mathrm{~N}_{2} \mathrm{OS}\right]^{+}, 305\left[\mathrm{M}-\mathrm{C}_{3} \mathrm{HN}_{2} \mathrm{OS}\right]^{+}, 292\left[\mathrm{M}-\mathrm{C}_{4} \mathrm{H}_{2} \mathrm{~N}_{2} \mathrm{OS}\right]$.

2.5.13. 2-(3-Nitrobenzylthio)-5-(2-nitrostyryl)-1,3,4-oxadiazole (6n)

Off-white amorphous solid; m.p. 82-84 ${ }^{\circ} \mathrm{C}$; yield $78 \%$; IR $\left(\mathrm{KBr}, v_{\max } \mathrm{cm}^{-1}\right)$ : $3050(\mathrm{Ar}-\mathrm{H}), 1685(\mathrm{C}=\mathrm{N}), 1552(\mathrm{Ar} \mathrm{C}=\mathrm{C}), 1538\left(\mathrm{NO}_{2}\right), 843(\mathrm{C}-\mathrm{N}){ }^{\prime}{ }^{\max } \mathrm{H}-\mathrm{NMR}$ $\left(400 \mathrm{MHz}, \mathrm{CDCl}_{3}\right): \delta 8.34$ (br s, $1 \mathrm{H}, \mathrm{H}-2$ "), 8.15 (br d, $J=8.0 \mathrm{~Hz}, 1 \mathrm{H}, \mathrm{H}-4$ "), $8.05\left(\mathrm{~d}, J=8.0 \mathrm{~Hz}, 1 \mathrm{H}, \mathrm{H}-3^{\prime}\right), 7.91$ (d, $\left.J=16.4 \mathrm{~Hz}, 1 \mathrm{H}, \mathrm{H}-8^{\prime}\right), 7.84$ (br d, $J=$ $7.6 \mathrm{~Hz}, 1 \mathrm{H}, \mathrm{H}-6$ "), 7.68 (m, 2H, H-4', H-6'), 7.51-7.56 (m, 2H, H-3", H-5”), $6.94\left(\mathrm{~d}, J=16.4 \mathrm{~Hz}, 1 \mathrm{H}, \mathrm{H}-7^{\prime}\right), 4.56\left(\mathrm{~s}, 2 \mathrm{H}, \mathrm{CH}_{2}-7^{\prime \prime}\right) ;{ }^{13} \mathrm{C}-\mathrm{NMR}(75 \mathrm{MHz}$, CD $\mathrm{OD}$ ): $\delta 165.1$ (C-2), 163.9 (C-5), 149.6 (C-3”), 148.5 (C-2'), 138.9 (C-7'), 138.2 (C-1"), 135.1 (C-5'), 133.2 (C-1'), 132.6 (C-6"), 132.4 (C-4'), 131.3 (C-5”), 129.2 (C-6'), 126.8 (C-4"), 126.3 (C-3'), 124.4 (C-2”), 110.7 (C-8') 34.5 (C-7"); HR-MS: [M] 384.3847 (Calcd. for $\mathrm{C}_{17} \mathrm{H}_{12} \mathrm{~N}_{4} \mathrm{O}_{5} \mathrm{~S}$; 384.3659 ); EIMS: $m / z 384[\mathrm{M}]^{+}, 338\left[\mathrm{M}-\mathrm{NO}_{2}\right]^{+}, 292\left[\mathrm{M}-\mathrm{N}_{2} \mathrm{O}_{4}\right]^{+}, 248{ }^{2}\left[\mathrm{M}^{-\mathrm{C}_{7}} \mathrm{H}_{6} \mathrm{NO}_{2}\right]^{+}, 310$ $[\mathrm{M}-\mathrm{CNOS}]^{+}, 284\left[\mathrm{M}-\mathrm{C}_{2} \mathrm{~N}_{2} \mathrm{OS}\right]^{+}, 271\left[\mathrm{M}-\mathrm{C}_{3} \mathrm{HN}_{2} \mathrm{OS}\right]^{+}, 258\left[\mathrm{M}-\mathrm{C}_{4} \mathrm{H}_{2} \mathrm{~N}_{2} \mathrm{OS}\right]$

\section{Enzyme Inhibition Assays}

1.1. Acetylcholinesterase ( $\mathrm{AChE}$ ) and butyrylcholinesterase (BChE) Assays

The $\mathrm{AChE}$ and $\mathrm{BChE}$ inhibition activities were performed according to the reported method ${ }^{20}$ with slight modifications. Total volume of the reaction

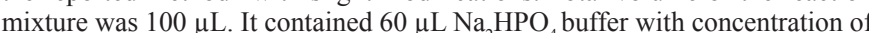
$50 \mathrm{mM}$ and $\mathrm{pH}$ 7.7. $10 \mu \mathrm{L}$ test compound $\left(0.5 \mathrm{mM}^{2}\right.$ well $\left.{ }^{-1}\right)$ was added, followed by the addition of $10 \mu \mathrm{L}\left(0.005\right.$ unit well $\left.^{-1}\right)$ enzyme. The contents were mixed and pre-read at $405 \mathrm{~nm}$. Then contents were pre-incubated for $10 \mathrm{~min}$ at $37^{\circ} \mathrm{C}$. The reaction was initiated by the addition of $10 \mu \mathrm{L}$ of $0.5 \mathrm{mM}$ well ${ }^{-1}$ substrate (acetylthiocholine iodide), followed by the addition of $10 \mu \mathrm{L}$ DTNB $(0.5 \mathrm{mM}$ well ${ }^{-1}$ ). After $15 \mathrm{~min}$ of incubation at $37^{\circ} \mathrm{C}$ absorbance was measured at 405 $\mathrm{nm}$ using 96 -well plate reader Synergy HT, Biotek, USA. All experiments were carried out with their respective controls in triplicate. Eserine $\left(0.5 \mathrm{mM}\right.$ well $\left.{ }^{-1}\right)$ was used as a positive control. The percent inhibition was calculated by the help of following equation

$I C_{50}$ values were calculated using EZ-Fit Enzyme kinetics software (Perrella Scientific Inc. Amherst, USA)

\subsection{Lipoxygenase (LOX) Assay}

Lipoxygenase activity was assayed according to the reported methods ${ }^{21-23}$ with slight modifications. A total volume of $200 \mu \mathrm{L}$ lipoxygenase assay mixture contained $150 \mu \mathrm{L}$ sodium phosphate buffer $(100 \mathrm{mM}, \mathrm{pH} 8.0), 10 \mu \mathrm{L}$ test compound and $15 \mu \mathrm{L}$ purified lipoxygenase enzyme (600 units well ${ }^{-1}$,Sigma Inc.). The contents were mixed and pre-read at $234 \mathrm{~nm}$ and preincubated for
10 minutes at $25{ }^{\circ} \mathrm{C}$. The reaction was initiated by addition of $25 \mu \mathrm{L}$ substrate solution. The change in absorbance was observed after $6 \mathrm{~min}$ at $234 \mathrm{~nm}$ using 96-well plate reader Synergy HT, Biotek, USA. All reactions were performed in triplicates. The positive and negative controls were included in the assay. Baicalin $\left(0.5 \mathrm{mM}^{-1}\right.$ well $\left.^{-1}\right)$ was used as a positive control. The percentage inhibition (\%) was calculated by formula given below.

Where Control $=$ Total enzyme activity without inhibitor

Test $=$ Activity in the presence of test compound

$I C_{50}$ values was calculated using EZ-Fit Enzyme Kinetics software (Perrella Scientific Inc. Amherst, USA).

\section{RESULTS AND DISCUSSION}

\subsection{Chemistry}

3-(2-nitrophenyl)acrylic acid (1) was converted to corresponding ester $\mathbf{2}$, hydrazide $\mathbf{3}$ and 1,3,4-oxadiazole 4, successively. Finally 6a-n derivatives of 4 were synthesized by reacting it with different electrophiles 5a-n (scheme 1). Structures of the synthesized compounds were elucidated and confirmed by IR, ${ }^{1} \mathrm{H}-\mathrm{NMR},{ }^{13} \mathrm{C}$-NMR, HR-MS and EI-MS techniques. For compound 4, the IR absorption band of aromatic C-H str. appeared at 3056 and a band at $1530 \mathrm{~cm}^{-1}$ indicated the presence of a nitro group while the peak at 1680 $\mathrm{cm}^{-1}(\mathrm{C}=\mathrm{N})$ was typical for an oxadiazole ring. Its molecular formula was confirmed through HR-MS showing molecular ion peak at $\mathrm{m} / \mathrm{z} 249.2685$, corresponding to $\mathrm{C}_{10} \mathrm{H}_{7} \mathrm{~N}_{3} \mathrm{O}_{3}$ (Calcd. for 249.2458). The EI-MS spectral data was also in complete agreement for the proposed structure of 5-(2-nitrostyryl)1,3,4-oxadiazole-2-thiol (4) which was finally confirmed through its ${ }^{1} \mathrm{H}-\mathrm{NMR}$ spectrum. The peaks at $\delta 8.06$ (dd, $\left.J=8.1,1.2 \mathrm{~Hz}, 1 \mathrm{H}, \mathrm{H}-3^{\prime}\right), 7.76$ (dd, $J=7.8$, $1.8 \mathrm{~Hz}, 1 \mathrm{H}, \mathrm{H}-6^{\prime}$ ), 7.74 (br t, $J=7.8, \mathrm{~Hz}, 1 \mathrm{H}, \mathrm{H}-4^{\prime}$ ), and 7.61 (ddd, $J=8.4$, $8.4,1.2 \mathrm{~Hz}, 1 \mathrm{H}, \mathrm{H}-5$ ') for aromatic protons and their splitting pattern confirmed that the ring was ortho-substituted, while the larger coupling constants for two olefinic protons at $\delta 7.89\left(\mathrm{~d}, J=16.2 \mathrm{~Hz}, 1 \mathrm{H}, \mathrm{H}-8^{\prime}\right)$, and $6.95(\mathrm{~d}, J=$ $16.2 \mathrm{~Hz}, 1 \mathrm{H}, \mathrm{H}-7^{\prime}$ ) disclosed their trans disposition. The structure was also thorough supported by its ${ }^{13} \mathrm{C}$-NMR spectrum. Similarly all other synthesized derivatives were characterized by aforesaid spectral techniques and screened for enzyme inhibitory activities to check their possible therapeutic potential for the treatment of various ailments associated with the over expression of studied enzymes.

\subsection{Enzyme Inhibition Activity:}

\subsubsection{AChE inhibitory potential}

All the synthesized compounds were screened against acetylcholinesterase and these molecules exhibited weak to moderate inhibitory potential against this enzyme (table 1). Among these, the parent molecule 4 exhibited relatively greater inhibitory potential having $I C_{50}$ value of $68.91 \pm 0.22 \mu \mathrm{M}$ relative to eserine, a reference standard, having a value of $0.04 \pm 0.001 \mu \mathrm{M}$. Moreover, it was also inferred that the substitution of various alkyl/aralkyl groups at the sulfur atom of the parent molecule $\mathbf{4}$ was not an effective tool to enhance the biological activity of such molecules against this enzyme.

\subsubsection{BChE inhibitory activity}

Butyrylcholinesterase inhibition potential was also analyzed for all these derivatives. Results (table 1) revealed that a number of derivatives posses moderate inhibitory potential against this enzyme. The molecule $\mathbf{6 n}$ showed better activity with $I C_{50}$ of $61.21 \pm 0.12 \mu \mathrm{M}$ which could be attributed to the substitution of 3-nitrobenzyl group in this molecule. The compounds $\mathbf{6 m}, \mathbf{6 c}$, $6 \mathbf{i}$ and $6 \mathbf{k}$ demonstrated an endurable potential with $I C_{50}$ values $73.21 \pm 0.17$, $74.51 \pm 0.11,80.31 \pm 0.21$ and $99.61 \pm 0.15 \mu \mathrm{M}$, respectively which depicted the impact of substitution of various moieties on the parent molecule.

\subsubsection{LOX inhibition potential}

A few of the synthesized compounds indicated very temperate potential against lipoxygenase (table 1 ). The molecule $\mathbf{6 m}$ exhibited better potential with $I C_{50}$ value of $28.11 \pm 0.11 \mu \mathrm{M}$. The compounds $6 \mathbf{b}, \mathbf{6 d}$ and $6 \mathbf{g}$ also bared a moderate inhibitory potential with $I C_{50}$ values of $99.61 \pm 0.18,85.75 \pm 0.11$ and $76.75 \pm 0.14$ respectively, relative to baicalein having the $I C_{50}$ value of $22.4 \pm 1.3$ $\mu \mathrm{M}$.

\subsubsection{Structure-activity relationship}

Overall, the heterocycle $6 \mathrm{~m}$ was found to exhibit inhibitory activity against all the three enzymes namely, acetylcholinesterase, butyrylcholinesterase and lipoxygenase, but inhibition activity against lipoxygenase is appreciable, while some compounds were active against butyrylcholinesterase while some others revealed inhibitory potential against lipoxygenase. The $6 \mathrm{~m}$ derivative possesses a $p$-bromobenzyl substitution on parent oxadiazole ring and mesomeric and inductive effect on parent moiety collectively could influence 
enzyme inhibition activity against all the three enzymes. However, the better inhibition potential by parent $\mathbf{4}$ against acetylcholinesterase enzyme revealed that the substitution of such groups was not a useful means to synthesize potent inhibitors of this enzyme. In compound $\mathbf{6 n}$, the substitution of $m$-nitrobenzyl group makes it a better entity as butyrylcholinesterase inhibitor. However, the compounds bearing olefinic group and $m$ - and $p$-substituted halogenated aromatic ring also rendered moderate inhibition against this enzyme.

\section{CONCLUSION}

The anticipated structures of the synthesized derivatives of 1,3,4-oxadiazole are well supported by spectroscopic analysis. The enzyme inhibition data help to conclude that the compounds reveal moderate activity against butyrylcholinesterase enzyme, and sound inhibitory potential against acetylcholinesterase and lipoxygenase enzymes, as it was evident from their $\mathrm{IC}_{50}$ values relative to the standard used. Hence, on the basis of aforesaid results, these synthesized derivatives provide an overall indispensable basis to introduce potent drugs. It is concluded from the described research work that halogenated aromatic substituted derivatives of 1,3,4-oxadiazoles seem valuable drug candidates for the treatment of Alzheimer and inflammatory diseases.

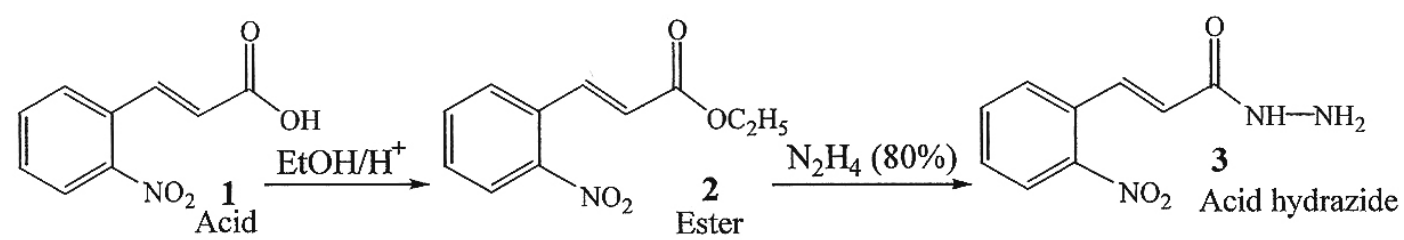<smiles>O=[N+]([O-])c1ccccc1/C=C/c1nnc(SF)o1</smiles>

S-Substituted 5-(2-nitrostyryl)1,3,4-oxadiazole
1. DMF, $\mathrm{NaH}$

$2 . \mathrm{R}-\mathrm{X}$

5a-n<smiles>[Y6][Y20](O)(O)c1nnc(S)o1</smiles>

5-(2-Nitrostyryl)-1,3,4 -oxadiazole-2-thiol

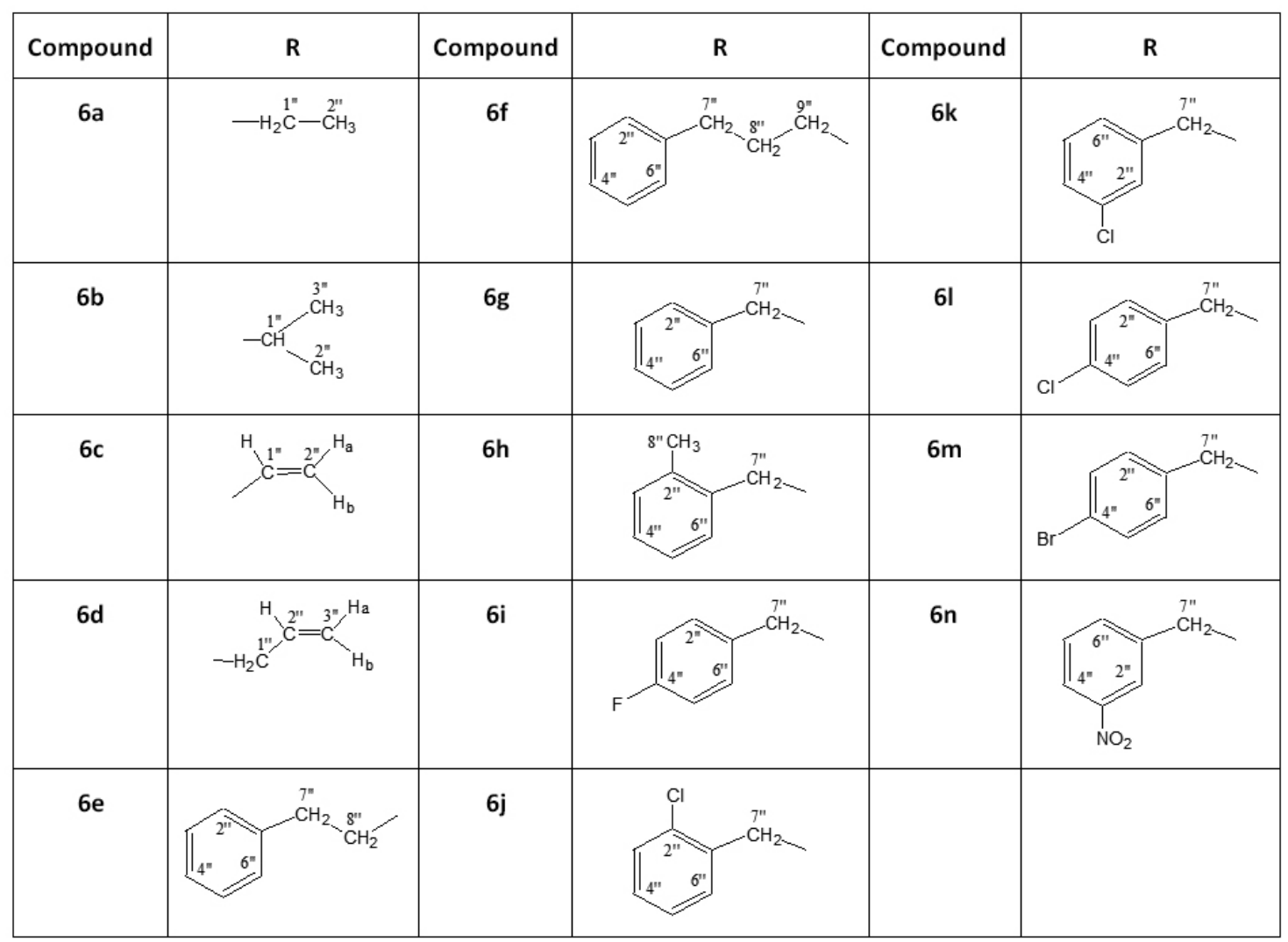

Scheme-1: Outline for the synthesis of $S$-substituted derivatives, 6a-n, of 5-(2-nitrophenyl)-1,3,4-oxadiazole-2-thiol (4) 
Table-1: Enzyme inhibition activity of $S$-substituted derivatives, 6a-n, of 5-(2-nitrophenyl)-1,3,4-oxadiazole-2-thiol (4).

\begin{tabular}{|c|c|c|c|c|c|c|}
\hline \multirow[b]{2}{*}{$\begin{array}{l}\text { S. } \\
\text { Code }\end{array}$} & \multicolumn{2}{|c|}{ AChE } & \multicolumn{2}{|c|}{ BChE } & \multicolumn{2}{|c|}{ LOX } \\
\hline & $\begin{array}{c}\text { Inhibition (\%) } \\
\text { Conc./well } \\
(0.5 \mathrm{mM}) \\
\end{array}$ & $\begin{array}{l}\text { IC }_{50} \\
\mu \mathrm{M}\end{array}$ & $\begin{array}{c}\text { Inhibition (\%) } \\
\text { Conc./well } \\
(0.5 \mathrm{mM})\end{array}$ & $\begin{array}{l}\mathbf{I C}_{50} \\
\mu \mathrm{M}\end{array}$ & $\begin{array}{c}\text { Inhibition (\%) } \\
\text { Conc./well } \\
(0.5 \mathrm{mM})\end{array}$ & $\begin{array}{l}\mathbf{I C}_{50} \\
\mu \mathrm{M}\end{array}$ \\
\hline 4 & $89.51 \pm 0.56$ & $68.91 \pm 0.22$ & $71.31 \pm 0.62$ & $115.41 \pm 0.22$ & $52.91 \pm 0.51$ & $>300$ \\
\hline 6a & $72.34 \pm 0.37$ & $135.21 \pm 0.31$ & $69.39 \pm 0.14$ & $132.61 \pm 0.12$ & $63.23 \pm 0.33$ & $201.31 \pm 0.23$ \\
\hline $6 \mathrm{~b}$ & $66.56 \pm 0.68$ & $254.61 \pm 0.18$ & $68.11 \pm 0.34$ & $138.71 \pm 0.18$ & $69.33 \pm 0.61$ & $99.61 \pm 0.18$ \\
\hline $6 c$ & $61.24 \pm 0.55$ & $301.21 \pm 0.19$ & $86.51 \pm 0.31$ & $74.51 \pm 0.11$ & $27.91 \pm 0.14$ & - \\
\hline $6 d$ & $57.41 \pm 0.68$ & $>400$ & $22.41 \pm 0.88$ & - & $73.65 \pm 0.32$ & $85.75 \pm 0.11$ \\
\hline $6 e$ & - & - & - & - & - & - \\
\hline $6 f$ & $62.13 \pm 0.22$ & $289.61 \pm 0.19$ & $70.97 \pm 0.91$ & $114.21 \pm 0.14$ & $61.92 \pm 0.87$ & $201.91 \pm 0.14$ \\
\hline $6 \mathrm{~g}$ & $54.88 \pm 0.52$ & $>400$ & $33.83 \pm 0.45$ & - & $71.51 \pm 0.58$ & $76.75 \pm 0.14$ \\
\hline $6 \mathrm{~h}$ & $53.71 \pm 0.85$ & $>400$ & $47.89 \pm 0.82$ & - & $63.95 \pm 0.18$ & $196.11 \pm 0.21$ \\
\hline $6 i$ & $53.41 \pm 0.61$ & $>400$ & $87.54 \pm 0.61$ & $80.31 \pm 0.21$ & $59.01 \pm 0.15$ & $>400$ \\
\hline $6 \mathbf{j}$ & $47.34 \pm 0.88$ & - & $65.94 \pm 0.66$ & $152.31 \pm 0.10$ & $31.69 \pm 0.71$ & - \\
\hline $6 \mathrm{k}$ & $32.54 \pm 0.64$ & - & $76.23 \pm 0.11$ & $99.61 \pm 0.15$ & $45.93 \pm 0.44$ & - \\
\hline 61 & $56.96 \pm 0.11$ & $>400$ & $71.77 \pm 0.21$ & $109.61 \pm 0.23$ & $37.79 \pm 0.21$ & - \\
\hline $6 m$ & $75.89 \pm 0.23$ & $101.21 \pm 0.17$ & $86.29 \pm 0.22$ & $73.21 \pm 0.17$ & $98.69 \pm 0.22$ & $28.11 \pm 0.11$ \\
\hline $6 n$ & $52.51 \pm 0.21$ & $>400$ & $90.78 \pm 0.24$ & $61.21 \pm 0.12$ & $54.51 \pm 0.27$ & $>400$ \\
\hline Control & $\begin{array}{c}\text { Eserine } \\
91.29 \pm 1.17\end{array}$ & $0.04 \pm 0.001$ & $\begin{array}{c}\text { Eserine } \\
82.82 \pm 1.09\end{array}$ & $0.85 \pm 0.0001$ & $\begin{array}{c}\text { Baicalein } \\
93.79 \pm 1.27\end{array}$ & $22.4 \pm 1.3$ \\
\hline
\end{tabular}

Note: $\mathrm{IC}_{50}$ values (concentration at which there is $50 \%$ enzyme inhibition) of compounds were calculated using EZ-Fit Enzyme kinetics software (Perella Scientific Inc. Amherst, USA).

$\mathrm{AChE}=$ Acetyl cholinesterase.

$\mathrm{BChE}=$ Butyrylcholinesterase.

LOX $=$ Lipoxygenase.

\section{REFERENCES}

1. F.A. Omar, N.M. Mahfouz, M.A. Rahman, Eur. J. Med. Chem. 31, 819, (1996)

2. B.N. Goswami, J.C.S. Kataky, J.N. Baruash, J. Heterocyclic Chem. 21, 205, (1984)

3. R. Alan, F.R. Katritzky, W. Charles, Comprehensive Heterocyclic Chemistry II, $1^{\text {st }}$ ed. UK: pergamon (1996)

4. S.J. Dolman, F. Gosselin, P.D. Oshea, I.W. Davis, J. Org. Chem. 71, 9548, (2006)

5. B.S. Holla, K.N. Poojary, B. Kalluraya, P.V. Gowda, Indian J. Heterocy. Chem. 5, 273, (1996)

6. K.Y. Matsumoto, Y. Yasuda, T. Tanimoto, K. Matsumoto, T. Yoshida, J. Shoji, J. Antibiot. 42, 1465, (1998)

7. S.S. Shafi, T.R. Radhakrishnan, Indian J. Heterocy. Chem. 5, 133, (1995)

8. A. Hasan, N.F. Thomas, S. Gapil, Molecules 16, 1297, (2011)

9. M.T. Omar, Arch. Pharm. Res. 20, 602, (1997)

10. T.M. Tan, Y.Chen, K.H. Kong, J. Bai, S.G. Li-Lim, H. Ang, Y. Lam. Antivir. Res. 71, 7, (2006)

11. S. Wagle, A.A. Vasudeva, N.K. Suchetha, Indian J. Chem. 47B, 439, (2008)
12. Nagaraj, K.C. Chaluvaraju, M.S. Niranjan, S. Kiran, Int. J. Pharm. Pharm. Sci. 3(3), 9, (2011)

13. S. Cao, X.H. Qian, G. Song, B. Chai, Z. Jiang, J. Agric. Food Chem. 51, $152,(2003)$

14. S.N. Pandeya, A textbook of medicinal chemistry, S.G. publishers, Varanasi p. 353, (2001)

15. B.N. Goswami, J.C. Kataky, M.M. Datta, Ind. J. Chem. 23B, 796, (1984)

16. R.S. Varma, V. Bajpai, Ind. J. heterocycl. Chem. 8, 281, (1999)

17. T.P. Dabhi, V.H. Shah, A.R. Parikh, Indian Drugs 54, 98, (1992)

18. Aziz-ur-Rehman, S.Z. Siddiqui, M.A. Abbasi, N. Abbas, K.M. Khan, M. Shahid, Y. Mahmood, M.N. Akhtar, and N.H. Lajis, Int. J. Pharm. Phram. Sci. 4(2), 676, (2012)

19. Aziz-ur-Rehman, K. Nafeesa, M.A. Abbasi, H. Khalid, K.M. Khan, M. Ashraf, I. Ahmad and S.A. Ejaz, Asian J. Pharma. Hea. Sci. 2(3), 370, (2012)

20. G.L. Ellman, K.D. Courtney, V. Andres, R.M. Featherstone, Bio. Pharm. 7, 88, (1961)

21. A.L. Tappel, Arch. Biochem. Biophys. 44(2), 378, (1953)

22. A.T. Evans, Bio Pharm. 36, 2035, (1987)

23. S. Baylac, P. Racine, Int. J. Aromatherap. 13, 138, (2003) 